\title{
Methanol Electrooxidation on Pt-Ru Catalysts Dispersed in Conducting Polyaniline Films
}

\author{
T. Kessler ${ }^{a}$, A.M. Castro Luna,,", W.E. Triacab \\ ${ }^{a}$ Facultad de Ingeniería. Universidad Nacional del Centro de la Provincia de Buenos Aires, \\ Avda. Del Valle 5737 (7400) Olavarría-Argentina \\ ${ }^{b}$ Instituto de Investigaciones Fisicoquímicas Teóricas y Aplicadas (INIFTA), Facultad de \\ Ciencias Exactas, Universidad Nacional de La Plata, Suc 4 CC 16 (1900) La Plata-Argentina
}

Received 09 March 2004; accepted in revised form 12 May 2004

\begin{abstract}
Methanol electrooxidation was investigated on tailored Pt-Ru-polyaniline catalysts prepared applying dynamic potential routines. The electrodes characterized by SEM, EDX and TEM present a uniform distribution of metal particles about $100 \mathrm{~nm}$ in size, composed of $\mathrm{Ru}$ and $\mathrm{Pt}$ on the fibrous polymer matrix. The effect of concentration in the range $0.05-1 \mathrm{M}$ and temperature in the range 20 to $60{ }^{\circ} \mathrm{C}$ on the methanol electrooxidation rate was determined. The apparent activation energy depends on the catalyst Ru content.
\end{abstract}

Keywords: polyaniline, ruthenium, platinum, methanol oxidation, activation energy.

\section{Introduction}

Electronic conducting polymers such as polypyrrol and polyaniline (Pani) are currently used as supports to incorporate metallic particles with the aim of obtaining new catalytic systems. On these matrices it is possible to get a better distribution of the particles because a three-dimensional array of the catalyst leads to a more efficient charge transport from the underlying support to the reaction site [1-6]. 
Using Pt as a catalytic material for the anode and cathode, in either the $\mathrm{H}_{2} / \mathrm{O}_{2}$ or methanol $/ \mathrm{O}_{2}$ fuel cell, the thermodynamic reversible cell potential in both arrangements is almost the same. Taking into account that methanol is easily stored, handled and produced from different sources, direct methanol oxidation in fuel cells represents a promising energy conversion system. However, under operating conditions high overpotentials affect the performance of the cell due to adsorbed carbonyl species from methanol, which block the Pt active sites and require an extra oxygen atom to free the surface giving $\mathrm{CO}_{2}$. Since water adsorbs at almost $0.6 \mathrm{~V}, \mathrm{Pt}$ anodes require excessive polarization to satisfy the oxygen demand. Thus, to improve the CO tolerance of Pt fuel cell anodes, the catalyst has to be modified conveniently, for example, by the addition of a second metal as co-catalyst. Transition metals that display one or several redox couples containing hydrous species at potentials close to that of hydrogen or methanol oxidation are mainly utilized [7,8]. Binary $\mathrm{Pt}-\mathrm{Ru}$ combinations have been reported to enhance $\mathrm{CO}$ tolerance and allow fuel cells to operate with both methanol and hydrogen coming from reforming [9-12].

Different types of Pt-Ru catalysts have been employed in methanol oxidation studies: well-defined alloys [13], polycrystalline Pt surfaces and single crystals modified by spontaneous $\mathrm{Ru}$ deposition [14,15], polycrystalline Pt surfaces modified by $\mathrm{Ru}$ electrodeposition [16], unsupported and dispersed catalysts supported on carbon and polymeric matrices $[5,6,10,17]$.

Volcano-shaped curves for catalytic activity versus catalyst composition have been observed at either low or high temperatures, for methanol electrooxidation on Pt-Ru catalysts indicating an identical methanol oxidation mechanism $[14,17]$. Moreover, it has been reported that an increase in temperature shifts the stripping peak potential of adsorbed carbonaceous species more negatively accounting for a lower activation barrier for the reaction [18]. Besides, effects of methanol concentration on the electrooxidation rate have been studied employing Pt-Ru bulk alloys [19] and Pt-Ru supported on carbon [12] concluding that an improvement in rate is achieved when methanol concentration increases. 
In this work, results about the effect of Ru content in the Pani-Pt-Ru catalysts on the methanol electrooxidation rate and the influence of methanol concentration and working temperature are discussed.

\section{Experimental details}

$\mathrm{Au}$ wires of $0.08 \mathrm{~cm}^{2}$ geometric area were used as substrates for polymer film deposition. A Au foil was employed as counter-electrode and a saturated calomel electrode as the reference. However, all the potentials in the text are referred to the reversible hydrogen electrode (RHE).

The preparation of the working electrode consists of a complex protocol that involves polymer preparation and catalysts dispersion. Pani films on Au were prepared in a $0.1 \mathrm{M}$ aniline $+0.5 \mathrm{M} \mathrm{H}_{2} \mathrm{SO}_{4}$ solution by applying cyclic voltammetry at $0.1 \mathrm{~V} \mathrm{~s}^{-1}$ between $-0.04 \mathrm{~V}$ and $0.92 \mathrm{~V}$; films with average thickness of about $0.5 \mu \mathrm{m}$ were employed. Afterwards, Pt or binary Pt-Ru particles were scattered onto Pani films using a repetitive square wave potential signal, RSWPS, between a lower potential $E_{1}=-0.2 \mathrm{~V}$ and an upper potential $\mathrm{E}_{\mathrm{u}}$ $=0.6 \mathrm{~V}$ with a frequency of $2.5 \mathrm{kHz}$ for an application time $\mathrm{t}$. The cathodic charge, $\mathrm{Q}_{\mathrm{d}}$, associated with metal deposition during the RSWPS treatment was measured. The solution to codeposit the metals was $0.1 \mathrm{M} \mathrm{HClO}_{4}$ containing $2 \times$ $10^{-2} \mathrm{M} \mathrm{H}_{2} \mathrm{PtCl}_{6}$ and $3.3 \times 10^{-2} \mathrm{M} \mathrm{RuCl}_{3}$. Real surface areas were determined considering the anodic charge involved under the CO stripping peak $\left(1 \mathrm{~cm}^{2}=420\right.$ $\mu \mathrm{C}$.

The electrocatalytic behaviour of the electrodes was examined through the stripping peak potential of adsorbed $\mathrm{CO}, \mathrm{E}_{\text {peakCO}}$. The catalytic electrodes were held at $0.05 \mathrm{~V}$ for $5 \mathrm{~min}$ in a $\mathrm{CO}$ saturated $0.5 \mathrm{M} \mathrm{H}_{2} \mathrm{SO}_{4}$ solution, then the $\mathrm{CO}$ in the electrolyte was removed by a nitrogen stream and finally a stripping voltammogram was recorded in the positive-going direction. Voltammetric current potential profiles for methanol oxidation have also been recorded. In chronoamperometric experiments, the quasi-steady oxidation currents at different anodic potentials in $0.5 \mathrm{M} \mathrm{CH}_{3} \mathrm{OH}+0.1 \mathrm{M} \mathrm{HClO}_{4}$ were obtained. Methanol concentration was varied between 0.05 and $1 \mathrm{M}$ and the working temperature 
between 18 and $48{ }^{\circ} \mathrm{C}$. EDX, SEM and TEM analyses were employed to characterize the catalysts.
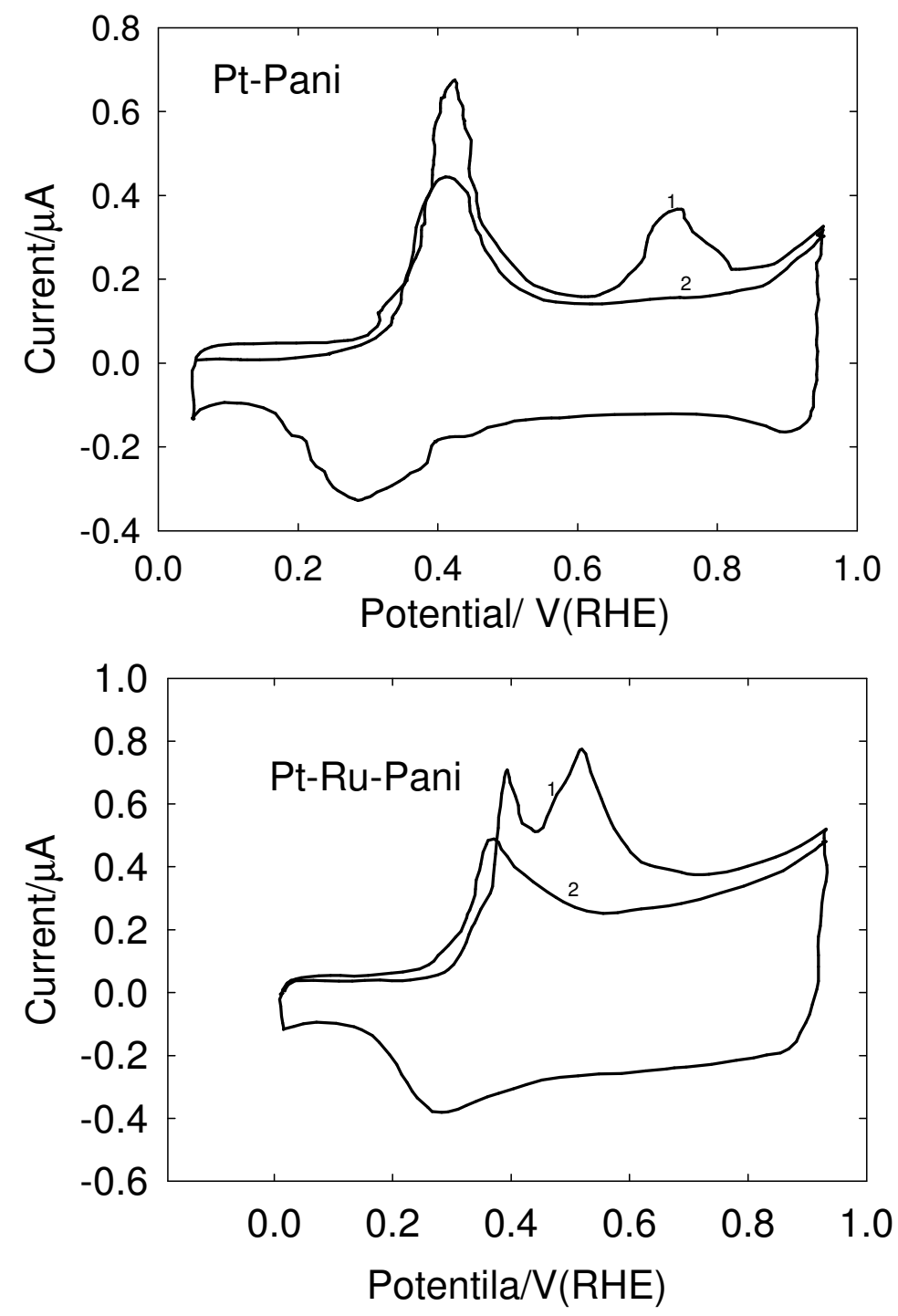

Figure 1. Stripping voltammograms of adsorbed CO on Pt-Pani (upper) and Pt-Ru Pani (lower) electrodes, Pani film: $0.5 \mu \mathrm{m}$ thickness, obtained applying RSWPS; v $=0.01 \mathrm{~V}$ $\mathrm{s}^{-1}$. The numbers in the curves correspond to the first and second cycles.

\section{Results and discussion}

\section{Electrooxidation improvement of adsorbed $\mathrm{CO}$}

CO stripping on Pt-Pani and Pt-Ru-Pani electrodes is shown in Fig. 1. In both voltammograms, the first anodic current peak corresponds to the conversion of leucoemeraldine to the protonated emeraldine form of Pani (at ca. 0.4 V). A 
second peak absent in the following cycles, attributed to $\mathrm{CO}$ stripping, is observed at ca. $0.73 \mathrm{~V}$ over Pt-Pani and at ca. $0.47 \mathrm{~V}$ over Pt-Ru-Pani. There is an important shift to lower potentials of $\mathrm{E}_{\text {peakCO }}$ when a Pt-Ru-Pani electrode is used. To explain the displacement on $\mathrm{Pt}-\mathrm{Ru}$ catalysts, the bifunctional mechanism is often invoked, with Pt sites being the ones where $\mathrm{CO}$ adsorbs and $\mathrm{Ru}$ sites those where oxygen species adsorb allowing the oxidative removal of adsorbed CO at lower potentials [19].

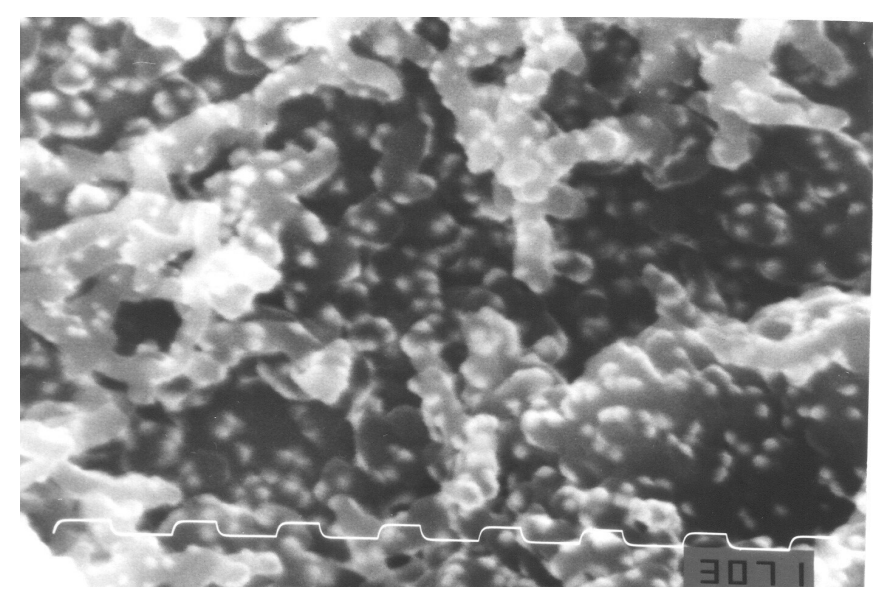

a)

b)

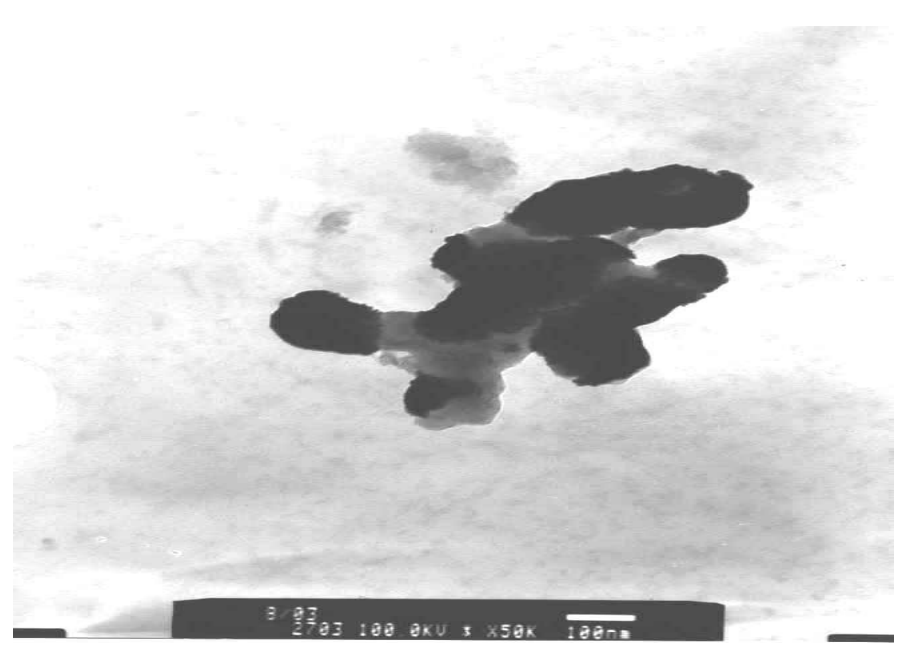

Figure 2. SEM micrograph (a), TEM micrograph (b) of a Pt-Ru-Pani electrode (EDX analysis 30 atom $\% \mathrm{Ru}$ ).

\section{Morphological aspects of modified electrodes}

The morphological aspects of Pt-Ru-Pani electrodes have been examined by SEM. The micrograph in Fig. 2a shows a polymeric three-dimensional matrix 
with randomly grown fibrous branches. Metallic particles are uniformly distributed on the whole film.

Table 1. Catalyst composition for different $Q_{d}$. Data derived from EDX analysis.

$\begin{array}{ccc}\mathrm{Q}_{\mathrm{d}} / \mathrm{C} & \mathrm{Pt} / \mathrm{atom} \% & \mathrm{Ru} / \text { atom } \% \\ 0.07 & 76 & 24 \\ 0.24 & 68 & 30 \\ 0.3 & 64 & 37\end{array}$

For Pt-Ru-Pani electrodes EDX analysis indicates a variable $\mathrm{Ru}$ atom percentage according to the cathodic charge, $\mathrm{Q}_{\mathrm{d}}$, measured during metal electrodeposition. The values of atom $\% \mathrm{Ru}$ content for different $\mathrm{Q}_{\mathrm{d}}$ are presented in Table $1 . \mathrm{Pt}$ deposits on Pani are achieved because the reduction of $\mathrm{Pt}(\mathrm{IV})$ to $\mathrm{Pt}(0)$ occurs at potentials above those corresponding to the first oxidation potential peak of the polymer that acts as a mediator in the metal deposition process. Pt-Ru deposits on Pani are obtained taking into account that $\mathrm{Pt}$ is easily reduced on the film and that the potential of zero charge for $\mathrm{Pt}$ is ca. $0.2 \mathrm{~V}$ and for $\mathrm{Ru}$ ca. $-0.25 \mathrm{~V}$ [20]. Thus, at $\mathrm{E}_{1}=-0.2 \mathrm{~V}, \mathrm{Pt}$ would be negatively charged and the deposition of $\mathrm{Ru}$ on $\mathrm{Pt}$ should be more rapid than on $\mathrm{Ru}$. Indeed, $\mathrm{Ru}$ ions need to have first $\mathrm{Pt}$ atoms on Pani in order to be reduced to $\mathrm{Ru}(0)$ [5]. Due to the conductive properties of the substrate once the deposition process starts, $\mathrm{Pt}$ is deposited on Pani and then $\mathrm{Ru}$ atoms are able to deposit over Pt atoms first and then over the first $\mathrm{Ru}$ atom row producing an irregular metal deposit with a column of $\mathrm{Ru}$ grown over Pt sites. Moreover, it is possible that the surface Ru content would be different from $\mathrm{Ru}$ bulk content due to a segregation process.

To determine the size of the catalytic particles, the decorated metal films were removed from the electrode by using an ultrasonic stirring bath in ethanol; drops of the alcoholic suspension were then deposited on a copper grid and analysed by TEM. In Fig. 2b, a TEM micrograph of a Pt-Ru deposit obtained for $\mathrm{Q}_{\mathrm{d}}=0.23 \mathrm{C}$ is shown. Black aggregates of metallic particles in the size range 50-100 $\mathrm{nm}$ are dispersed onto the greyish polymer matrix. 


\section{Influence of RSWPS duration}

In order to establish the best distribution of the catalytic particles onto the film, the variation of the real area as a function of the catalyst deposition charge was evaluated. A quasi-linear relationship between area and deposition charge up to $0.2 \mathrm{C}$ is observed in Fig. 3. The upper $\mathrm{Q}_{\mathrm{d}}$ value of the linear region determines the RSWPS cathodic charge required to achieve the best particle dispersion, since the real surface area remains almost constant for greater $Q_{d}$ values due to coalescence processes yielding larger particles.

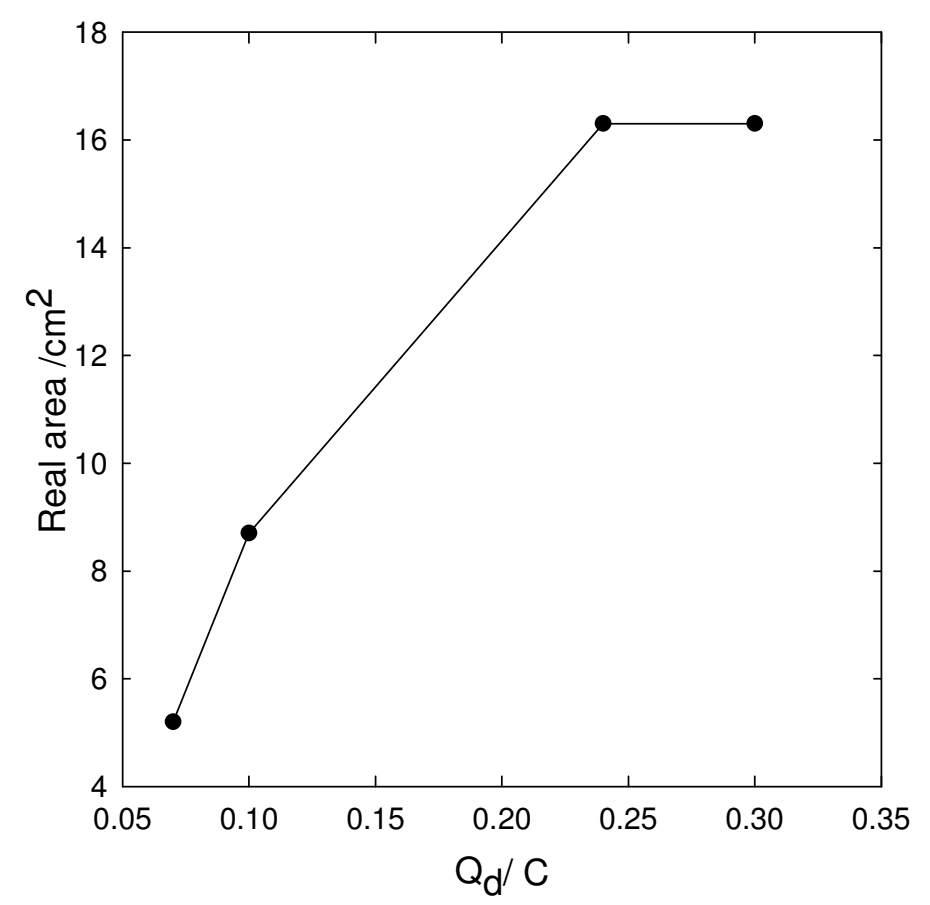

Figure 3. Dependence of the tailored catalyst real area on the cathodic charge $Q_{d}$.

\section{Influence of $R u$ atom percentage on methanol oxidation rate}

Different Pt-Ru-Pani electrodes, with $\mathrm{Ru}$ content determined through EDX analysis, were employed to study the oxidation of methanol. Methanol oxidation current density values at $0.5 \mathrm{~V}$ versus atom $\% \mathrm{Ru}$ content, at room temperature are shown in Fig. 4. The Pt-Pani electrode performance was also included for comparison purposes. For either sole $\mathrm{Pt}$ or high $\mathrm{Ru}$ atom percentage in the $\mathrm{Pt}-\mathrm{Ru}$ 
combination, a low activity was measured, with ca. 30 atom $\% \mathrm{Ru}$ being the suitable amount to attain the best performance.

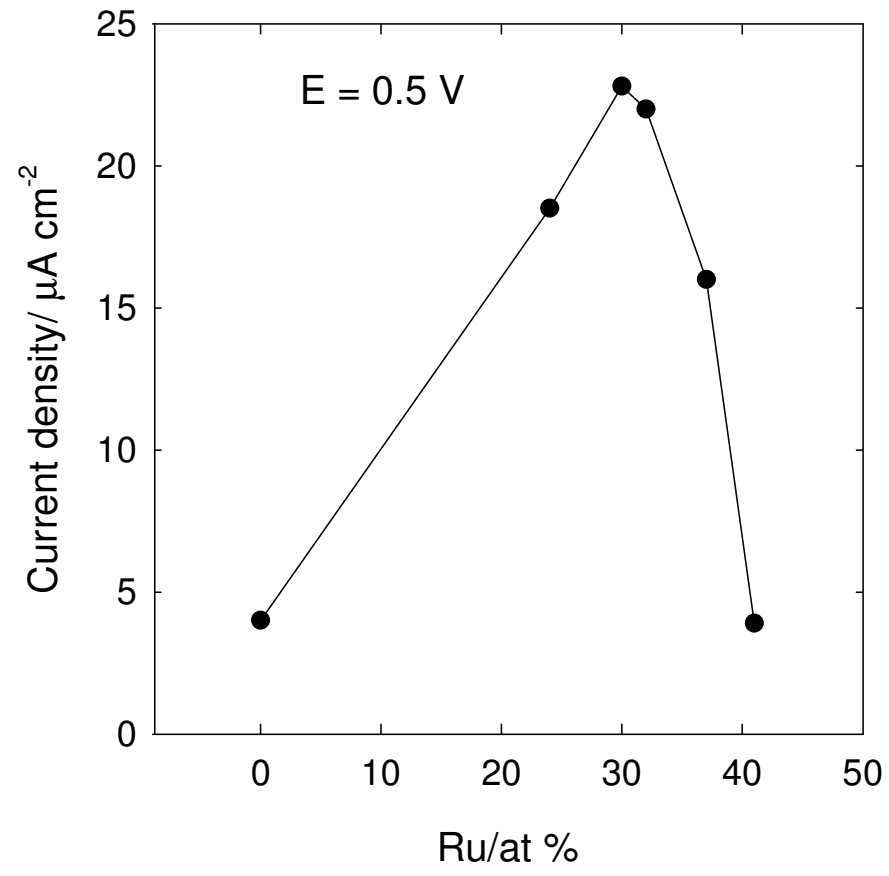

Figure 4. Dependence of the $0.5 \mathrm{M} \mathrm{CH}_{3} \mathrm{OH}$ oxidation current densities after $10 \mathrm{~min}$ at $\mathrm{E}=0.5 \mathrm{~V}$ as a function of the $\mathrm{Ru}$ content of the catalyst.

\section{Influence of temperature}

The performance of Pt-Ru-Pani electrodes for methanol oxidation was improved by increasing the temperature. It is well known that at temperatures above $40{ }^{\circ} \mathrm{C}$ methanol is also adsorbed and oxidized on $\mathrm{Ru}$ [21]. Thus, methanol oxidation currents recorded during a positive-going potential scan at $0.01 \mathrm{~V} \mathrm{~s}^{-1}$ at different temperatures are presented in Fig. 5a. It is noted that at higher temperatures, the onset of the oxidation reaction is shifted towards the thermodynamic potential for methanol oxidation $(0.02 \mathrm{~V})$. In Fig. $5 \mathrm{~b}$ the current density values after $10 \mathrm{~min}$ at $\mathrm{E}=0.5 \mathrm{~V}$ as a function of temperature show that an almost threefold current density increase takes place when temperature doubles. Tafel slopes for methanol oxidation are seldom reported due to the absence of a wide linear E versus $\log \mathrm{i}$ relationship [22]. Tafel slopes of ca. $150 \mathrm{mV}$ decade $^{-1}$ were determined for 
catalysts with 30 atom $\% \mathrm{Ru}$, in the potential range $0.5-0.65 \mathrm{~V}$ and in the temperature range $28-48^{\circ} \mathrm{C}$.
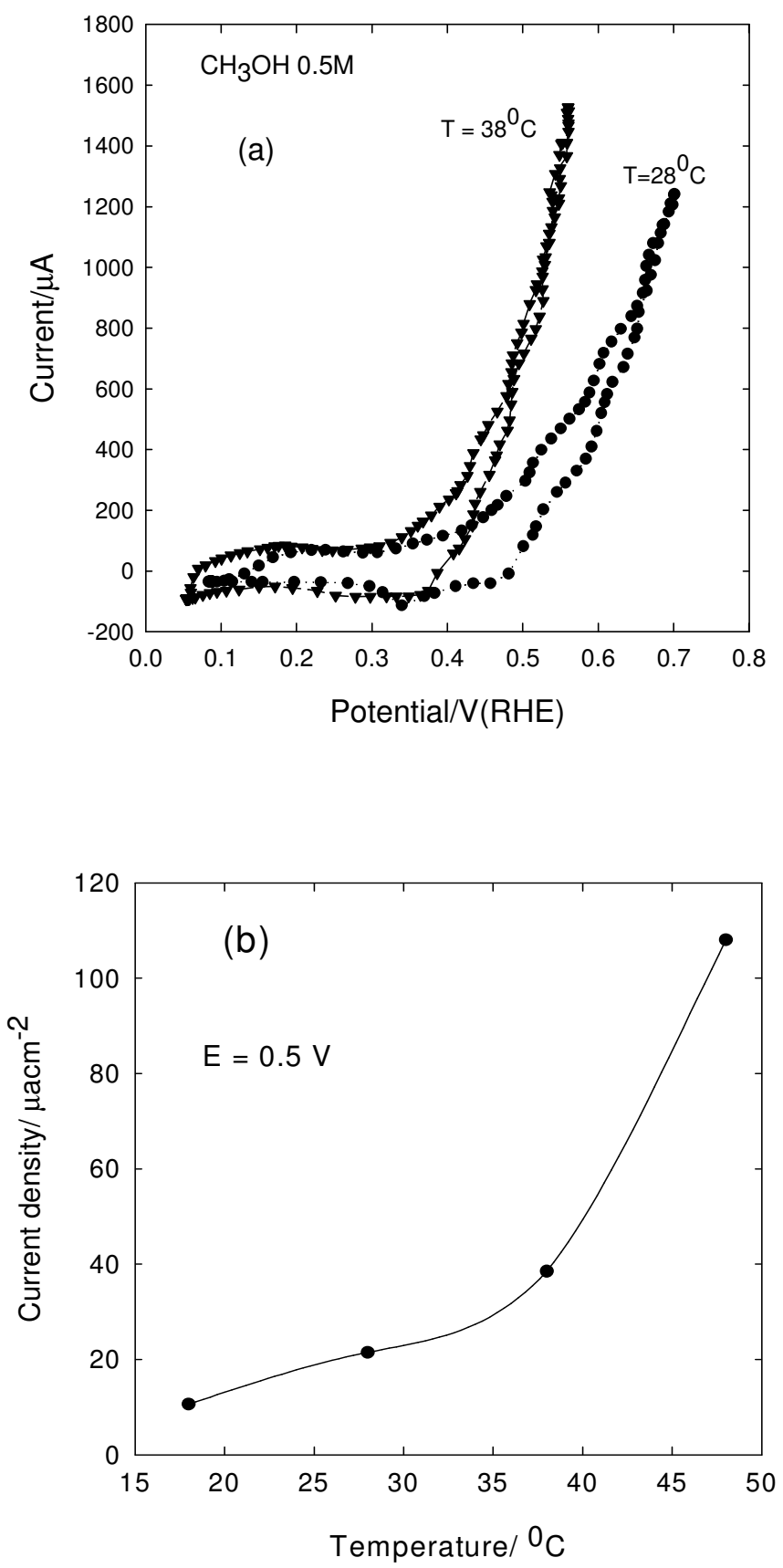

Figure 5. (a) Voltammetric current potential profile recorded at $\mathrm{v}=0.01 \mathrm{~V} \mathrm{~s}^{-1}$ and $(\bullet) \mathrm{T}$ $=28{ }^{\circ} \mathrm{C}$ and $(\boldsymbol{\nabla}) \mathrm{T}=38{ }^{\circ} \mathrm{C}$ in $0.5 \mathrm{M} \mathrm{CH}_{3} \mathrm{OH}$. (b) Dependence of the $0.5 \mathrm{M} \mathrm{CH}_{3} \mathrm{OH}$ oxidation current densities after $10 \mathrm{~min}$ at $\mathrm{E}=0.5 \mathrm{~V}$ as a function of temperature. 


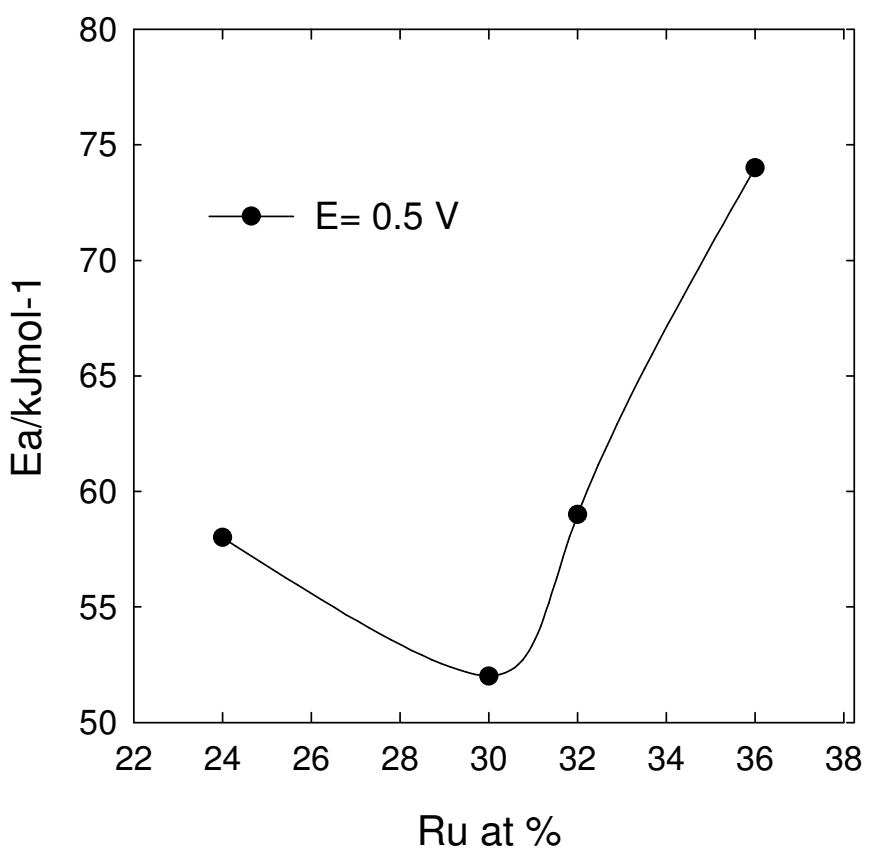

Figure 6. Dependence of the apparent activation energy for $0.5 \mathrm{M} \mathrm{CH}_{3} \mathrm{OH}$ with the $\mathrm{Ru}$ content of the catalyst at $\mathrm{E}=0.5 \mathrm{~V}$.

The apparent activation energy, $E_{a}$, for the methanol oxidation reaction was estimated from Arrhenius plots. Different $E_{a}$ values were found at $\mathrm{E}=0.5 \mathrm{~V}$ for $\mathrm{Pt}-\mathrm{Ru}$ electrodes with a variable Ru content (Fig. 6). Thus, for the catalyst with a lower Ru content, $E_{a}$ was $58 \mathrm{~kJ} \mathrm{~mol}^{-1}$, while $E_{a}$ increased to almost $75 \mathrm{~kJ} \mathrm{~mol}^{-1}$ for catalysts with higher Ru content, and a minimum $E_{a}=52 \mathrm{~kJ} \mathrm{~mol}^{-1}$ was found at 30 atom $\% \mathrm{Ru}$. It has been reported that $E_{a}$ values for Pt-Ru catalysts vary significantly depending on the surface composition, electrolyte concentration and applied potential [23-26]. A change in the rate determining step from methanol adsorption/dehydrogenation to the surface migration of adsorbed $\mathrm{CO}$ on Pt-rich surfaces was postulated to explain changes in $E_{a}$ with $\mathrm{Ru}$ surface content. The possibility for $\mathrm{CO}$ to diffuse from $\mathrm{Pt}$ sites to regions of hydroxyl adsorbed $\mathrm{Ru}$ sites that catalyze the oxidation of $\mathrm{CO}$ to $\mathrm{CO}_{2}$ provides a means to free the surface of adsorbed partial oxidation products and expose clean metal atom assemblies to continue methanol oxidation reaction. This is the prevalent mechanism on Pt-rich alloys [13]. The dynamic situation at the surface can explain the $E_{a}$ value variation shown in Fig. 7. 

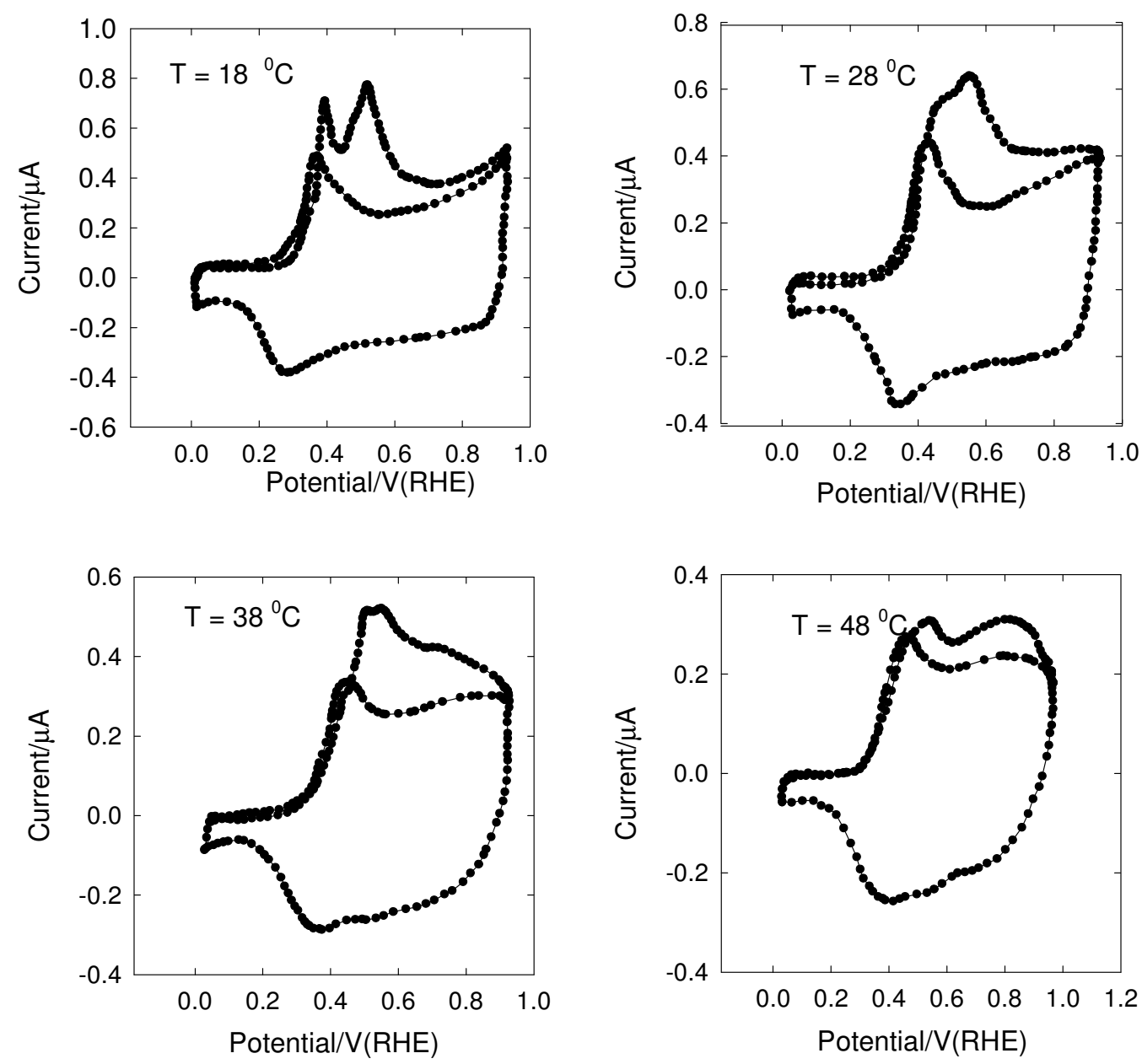

Figure 7. Stripping voltammograms of adsorbed $\mathrm{CO}$ on a Pt-Ru-Pani electrode after working at different temperatures; $\mathrm{v}=0.01 \mathrm{~V} \mathrm{~s}^{-1}$.

The real surface area value at each temperature was determined by performing the CO stripping voltammograms that are shown in Fig. 7. Real surface area diminished with increasing temperature. Correspondingly, methanol oxidation current densities were referred to these real surface area values. It is important to remark that at high temperatures a considerable broadening and an anodic potential shift of the first oxidation peak of Pani occur, revealing that the polymer was subjected to deterioration and degradation processes [27]. It has been reported that $\mathrm{HCHO}, \mathrm{HCOOH}$ and $\mathrm{HCOOCH}_{3}$ are possible reaction intermediate products in methanol electrooxidation. The yields of these products depend on methanol concentration, temperature, electrode roughness and time of electrolysis [28]. 


\section{Influence of methanol bulk concentration}

The dependence of the current density on methanol concentration at $0.5 \mathrm{~V}$ and $48{ }^{\circ} \mathrm{C}$ for a Pt-Ru-Pani electrode, 30 atom \% Ru, is shown in Fig. 8. The current density increases sharply from $0.005 \mathrm{M}$ to ca. $0.2 \mathrm{M}$; then it grows at a moderate rate. An estimated half-order kinetics with respect to methanol concentration is determined in the potential range $0.5-0.65 \mathrm{~V}$. The same value was estimated by Bagotzsky [29] for smooth and platinized Pt electrodes in acid solutions containing from $10^{-4}$ to $2 \mathrm{M} \mathrm{CH}_{3} \mathrm{OH}$ and by Gojkovic et al. [22] for Pt-Ru electrodes.

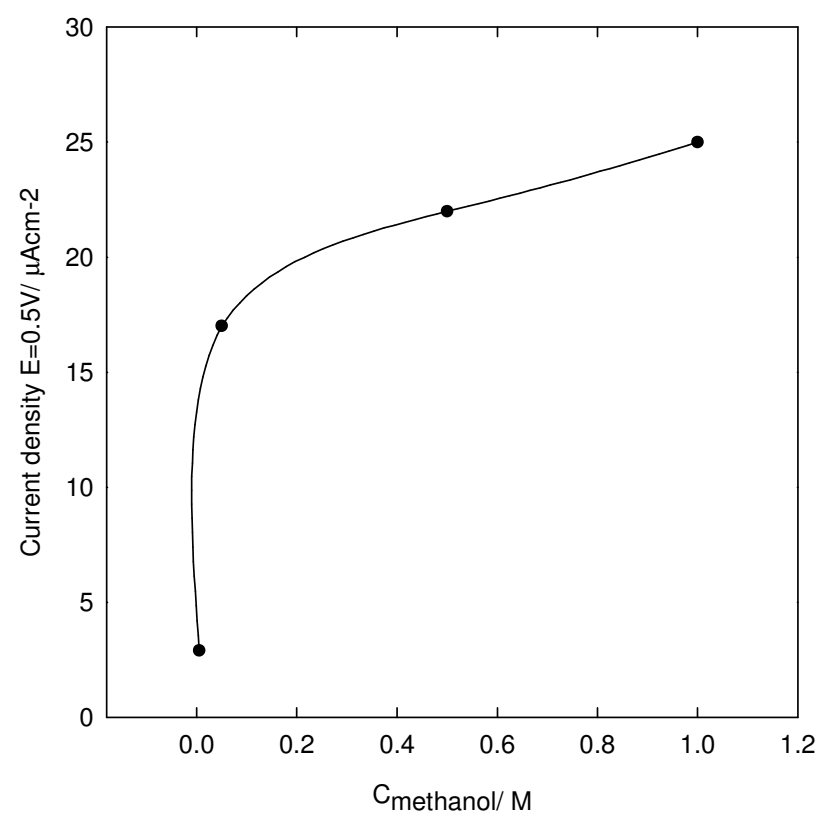

Figure 8. Oxidation current density at $0.5 \mathrm{~V}$ and $48{ }^{\circ} \mathrm{C}$ versus methanol bulk concentration.

\section{Conclusions}

1- Polyaniline films are appropriate substrates to electrodisperse catalytic metals.

2- Catalytic electrodes for carbon monoxide and methanol oxidation are prepared by codeposition of $\mathrm{Ru}$ and $\mathrm{Pt}$ onto polyaniline films through an RSWPS treatment from suitable Ru(III) and Pt(IV) ion solutions.

3- Temperature increases favour methanol oxidation rate. 
4- Tafel slopes vary between 120 and $170 \mathrm{mV} /$ decade and the apparent activation energy, $E_{a}$, between $50-75 \mathrm{~kJ} \mathrm{~mol}^{-1}$ depending on Ru content.

5- Degradation and deterioration processes affect the substrate at high temperatures.

6- Methanol oxidation rate increases with methanol concentration. The reaction order with respect to methanol concentration is ca. 0.5 .

\section{Acknowledgements}

The authors are grateful to Comisión de Investigaciones Científicas de la Provincia de Buenos Aires (CIC) and Agencia Nacional de Promoción Científica y Tecnológica de Argentina for financial support.

T.K. and A.M.C.L. are members of the research career at CIC.

\section{References}

1. H. Laborde, J.M. Leger, C. Lamy, J. Appl. Electrochem. 24 (1994) 1019.

2. A.A. Mikhaylova, E.B. Molodkina, O.A. Khazova, V.S. Bagotzky, J. Electroanal. Chem. 509 (2001) 119.

3. K. Bouzek, K.M. Mangold, K. Juttner, J. Appl. Electrochem. 31 (2001) 501.

4. A.M. Castro Luna, J. Appl. Electrochem. 30 (2000) 1137.

5. T. Kessler, A.M. Castro Luna, J. Appl. Electrochem. 32 (2002) 825.

6. T. Kessler, A.M. Castro Luna, J. Solid State Electrochem. 7 (2003) 593.

7. A. Anderson, E. Grantscharova, S. Seong, J. Electrochem. Soc. 143 (1996) 2075.

8. E. Reddington, A. Sapienza, B. Gurrar, R. Viswanathan, S. Sarangapani, E.S. Smotkin, T.E. Mallouk, Science 280 (1998) 1735.

9. D.R. Rolison, P.L. Hagans, K.S. Swider, J.W. Long, Langmuir 15 (1999) 774-779.

10. V. Radmilovic, H.A. Gastgeiger, P.N. Ross Jr, J. Catalysis 154 (1995) 98.

11. P. Waszczuk, G.Q. Lu, A. Wieckowski, C. Lu, C. Rice, R.I. Masel, Electrochim. Acta 47 (2002) 3637.

12. W.H. Lizcano-Valbuena, V.A. Paganin, E.R. Gonzalez, Electrochim. Acta 47 (2002) 3715. 
13. H.A. Gasteiger, N. Markovic, P.N. Ross and E.J. Cairns, J. Electrochem. Soc. 141 (1994) 1795.

14. M. Watanabe, Y. Genjima, K. Turumi, J. Electrochem. Soc. 144 (1997) 423.

15. W. Chzanowski, A. Wieckowski, Langmuir 14 (1998) 1967.

16. Y. Morimoto, E.B. Yeager, J. Electroanal. Chem. 444 (1998) 95.

17. A.S. Aricó, P.L. Antonucci, E. Modica, V. Baglio, H. Kim, V. Antonucci, Electrochim. Acta 47 (2002) 3723.

18. A.S. Aricó, V. Baglio, A. Di Blasi, E. Modica, P.L. Antonucci, V. Antonucci, J. Electroanal. Chem. 557 (2003) 167.

19. H.A. Gasteiger, N. Markovic, P.N. Ross and E.J. Cairns, J. Phys. Chem. 97 (1993) 12020.

20. J.F. Llopis, I.M. Tordesillas, in "Encyclopedia of Electrochemistry of the Elements”, A. Bard, Ed., Vol. VI, Marcel Dekker Inc., 1976, p. 277.

21. D. Chu, S. Gilman, J. Electrochem. Soc. 143 (1996) 1685.

22. S.Lj. Gojkovic, T.R. Vidakovic, D.R. Durovic, Electrochim. Acta 48 (2003) 3607.

23. T.J. Schmidt, H.A. Gasteiger, R.J. Behm, Electrochem. Commun. 1 (1999) 1.

24. A. Aramata,T. Kodera, M. Masuda, J. Appl. Electrochem. 18 (1988) 577.

25. A.S. Aricó, E. Modica, E. Passalacqua, V. Antonucci, P.L. Antonucci, J. Appl. Electrochem. 27 (1997) 1275.

26. C.E. Lee, S.H. Bergens, J. Phys. Chem. B 102 (1998)193.

27. D.E. Stilwell, Su-Moon Park, J. Electrochem. Soc. 135 (1988) 2497.

28. T. Iwasita, Electrochim. Acta 47 (2002) 3663.

29. V.S. Bagotzski, T.B. Vassilyev, Electrochim. Acta 12 (1967) 1323. 